\title{
Treatment of renal fibrosis by rebalancing TGF- $\beta /$ Smad signaling with the combination of asiatic acid and naringenin
}

\author{
Xiao-ming Meng ${ }^{1,2}$, Yun Zhang ${ }^{1,3}$, Xiao-Ru Huang1, Gui-ling Ren², Jun Li² and Hui \\ Yao Lan ${ }^{1}$ \\ ${ }^{1}$ Department of Medicine and Therapeutics, Li Ka Shing Institute of Health Sciences, Shenzhen Research Institute, The \\ Chinese University of Hong Kong, Hong Kong SAR \\ ${ }^{2}$ School of Pharmacy, Anhui Medical University, An Hui, China \\ ${ }^{3}$ Department of Dermatology, Foshan Hospital of TCM, Foshan, China \\ Correspondence to: Hui Yao Lan, email: hylan@cuhk.edu.hk

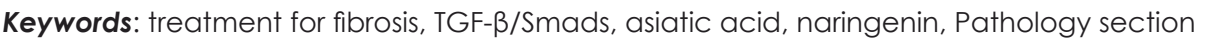 \\ Received: July 08, 2015 \\ Accepted: September 09, 2015 \\ Published: October 12, 2015
}

This is an open-access article distributed under the terms of the Creative Commons Attribution License, which permits unrestricted use, distribution, and reproduction in any medium, provided the original author and source are credited.

\section{ABSTRACT}

We recently showed that imbalance of TGF- $\beta$ /Smad signaling with over-activation of Smad3 but lower levels of Smad7 is a central mechanism of tissue fibrosis. In the present study, we report here that inhibition of Smad3 with naringenin (NG) and upregulation of Smad7 with asiatic acid (AA) produced an additive effect on inhibition of renal fibrosis in a mouse model of obstructive nephropathy. We found that AA, a triterpene from Centella Asiatica, functioned as a Smad7 agonist and suppressed TGF- $\beta$ /Smad3-mediated renal fibrosis by inducing Smad7. Whereas, NG, a flavonoid from grapefruits and citrus fruits, was a Smad3 inhibitor that inhibited renal fibrosis by blocking Smad3 phosphorylation and transcription. The combination of AA and NG produced an additive effect on inhibition of renal fibrosis by blocking Smad3 while upregulating Smad7. Thus, rebalancing the disorder of TGF- $\beta /$ Smad signaling by treatment with AA and NG may represent as a novel and effective therapy for chronic kidney disease associated with fibrosis.

\section{INTRODUCTION}

Renal fibrosis, characterized by the accumulation of myofibroblasts and extracellular matrix (ECM), is a major cause of the end-stage renal disease. However, treatment of renal fibrosis remains non-specific and ineffective clinically. Increasing evidence shows that TGF- $\beta 1$ is a key mediator of renal fibrosis [1-5]. Many studies have attempted to develop anti-fibrosis therapy by inhibiting the upstream of TGF- $\beta$ signaling, including antisense TGF- $\beta$ oligodeoxynucleotides, neutralizing antibodies, and inhibitors to TGF- $\beta$ receptor (T $\beta R$ ) kinases in a variety of kidney disease models [2, 6-8]. However, treatment of puromycin aminonucleoside nephropathy with a high dose of anti-TGF- $\beta$ antibody produces no renoprotective effect [9], which is consistent with a recent finding that disruption of TGF- $\beta$ type II receptor decreased renal fibrosis but enhanced renal inflammation [10]. Results from these studies suggest that inhibiting the upstream of TGF- $\beta$ signaling may not be an optimal therapeutic approach due to the diverse roles of TGF- $\beta 1$ in inflammation and fibrosis. Although blockade of the upstream TGF- $\beta$ signaling inhibits fibrosis, it may also promote inflammation. Therefore, we hypothesized that treatment of renal fibrosis should target the downstream TGF- $\beta /$ Smad signaling associated with fibrosis, rather than to block the general effect of TGF- $\beta 1$.

Increasing evidence shows that TGF- $\beta /$ Smad signaling is a central pathway leading to renal fibrogenesis [1]. It is now clear that TGF- $\beta 1$ promotes fibrosis positively by activating its downstream molecule Smad3, not Smad2, but negatively by an inhibitory Smad7 $[2,11]$. In the context of fibrosis, Smad3 is pathogenic, which is supported by the finding that mice lacking Smad3 are protected against tissue fibrosis in chronic kidney and cardiac diseases [12-15]. In contrast, Smad7 is protective during fibrosis as deletion of Smad7 promotes, but overexpression of Smad7 inhibits, tissue fibrosis [16-19]. Thus, the imbalance of TGF- $\beta /$ Smad signaling may be a major cause of renal fibrosis and rebalancing this pathway 
by inactivating Smad3 while upregulating Smad7 may produce a better therapeutic effect on renal fibrosis.

Asiatic Acid (AA), a triterpenoid component extracted from Centella asiatica [20], has been shown to have a variety of pharmacological effects including anti-inflammation [21], anti-oxidation [22] and antifibrosis $[23,24]$. We recently found that AA exerts its anti-fibrotic effects on liver fibrosis by inducing Smad7 [23]. Naringenin (NG) is a flavonoid from grapefruit and citrus fruits with anti-inflammatory properties in a number of disease conditions including atherosclerosis and diabetes [25-27]. NG is also found to inhibit TGF- $\beta /$ Smad3 signaling and tissue fibrosis including epithelialmesenchymal transition in a number of disease models $[28,29]$. Based on these observations, we therefore hypothesized that the combination of AA and NG may produce a better therapeutic effect on renal fibrosis by more effectively correcting the imbalance of TGF- $\beta$ / Smad signaling, namely upregulation of Smad7 while suppressing Smad3. The hypothesis was examined in the present study in vitro and in a well-characterized mouse model of unilateral ureteral obstruction (UUO).

\section{RESULTS}

\section{Combination of AA and NG produces a better effect on restoring the balance of TGF- $\beta / \mathrm{Smad}$ signaling and inhibiting TGF- $\beta 1$-induced fibrosis in vitro}

We first determined an effective and safe dosage of $\mathrm{AA}$ and $\mathrm{NG}$ in vitro, in which a better effect on restoring the balance of TGF- $\beta /$ Smad signaling and inhibiting fibrosis without cytotoxicity was achieved. As shown in Figure 1A, phosphorylation of Smad3 was significantly induced in renal tubular epithelial cells (TECs) at 30 minutes after addition of TGF- $\beta 1(2 \mathrm{ng} / \mathrm{ml})$, which was significantly inhibited by over-night pre-incubation with AA at dosages of $20 \mu \mathrm{M}$ and $30 \mu \mathrm{M}$ (Figure 1a). Similarly, addition of NG was also able to block TGF$\beta 1$-induced activation of Smad3 in a dosage-dependent manner, with significant dosages over $50 \mu \mathrm{M}$ (Figure 1b). We then examined the cytotoxic response to AA or NG in cultured TECs. As shown in Figure 1c and 1d, lactate dehydrogenase (LDH) releasing assay and MTT assay detected that AA at concentrations over $30 \mu \mathrm{M}$ caused significant cytotoxicity and largely decreased cell viability of TECs. In contrast, the cytotoxic and anti-proliferation effects of NG were undetectable with the concentration range from $25 \mu \mathrm{M}$ to $400 \mu \mathrm{M}$ (Figure 1c and 1d). Taken together, AA at $20 \mu \mathrm{M}$ and $\mathrm{NG}$ at $50 \mu \mathrm{M}$ were selected as an effective and safe dosage for the in vitro study. Furthermore, the combination of AA $(20 \mu \mathrm{M})$ and NG $(50 \mu \mathrm{M})$ also produced no cytotoxicity to TECs (Figure 1c).

After determining an effective and safe dosage of $\mathrm{AA}, \mathrm{NG}$, and their combination use, the mechanisms of drugs actions were examined in TGF- $\beta 1$-stimulated TECs. Real-time PCR and Western blot showed that addition of AA induced upregulation of Smad7 at both mRNA and protein levels, which was associated with inhibition of Smad3 phosphorylation but not expression (Figure 1a, Figure 2). These observations suggested that AA acts by inducing Smad7 to inhibit TGF- $\beta 1$-induced Smad3 signaling. Similarly, addition of NG was capable of blocking TGF- $\beta 1$-induced phosphorylation of Smad3 (Figs. $1 \mathrm{~b}$ and Figure $2 \mathrm{~b}$ ). Interestingly, $\mathrm{NG}$ also inhibited expression of Smad3 in both mRNA and protein levels (Figure 2); however, treatment with NG failed to induce Smad7 transcription (Figure 2a ii), revealing that NG inhibits TGF- $\beta /$ Smad3 signaling by blocking Smad3 phosphorylation and transcription.

Because AA and NG acted by different mechanisms to inhibit TGF- $\beta /$ Smad signaling, we tested if the combination of AA and NG produces a better inhibitory effect on TGF- $\beta /$ Smad signaling and fibrosis. As shown in Figure 2, although the combination of AA $(20 \mu \mathrm{M})$ and $\mathrm{NG}$ $(50 \mu \mathrm{M})$ produced little additive effect on mRNA levels of Smad3 or Smad7 (Figure 2a i, ii), TGF- $\beta 1$-induced phosphorylation of Smad3 and expression of Smurf2 were additively suppressed (Figure 2b). Real-time PCR and Western blot revealed that the combined treatment with AA and NG also produced an additive inhibitory effect on TGF- $\beta 1$-induced collagen I and $\alpha$-SMA expression in TGF- $\beta 1$-stimulated TECs (Figure 3). However, the combination of AA and NG produced no additive effect on inhibition of TGF- $\beta 1$ mRNA expression (Figure 2a iii).

\section{Combination treatment with AA and NG produces a better anti-fibrotic effect on UUO nephropathy in vivo}

We next examined if the combination of AA and NG also produced a better inhibitory effect on renal fibrosis in a well-established mouse model of UUO. We first determined an optimal dosage of AA and NG and their combination for a better anti-fibrosis effect without toxicity in a mouse model of UUO. As shown in Figure 4, daily intraperitoneal injection (i.p.) of AA for 7 days was able to inhibit collagen I expression in the UUO kidney in a dose-dependent manner, with a better inhibitory effect at dosages of 5 and $10 \mathrm{mg} / \mathrm{kg}$ body weight (BW). In addition, i.p. injection of $\mathrm{NG}$ also dose-independently inhibited collagen I production in the UUO kidney, with an optimal dosage at $50 \mathrm{mg} / \mathrm{kg} \mathrm{BW}$. Thus, AA at $5 \mathrm{mg} / \mathrm{kg} \mathrm{BW}$ and NG at $50 \mathrm{mg} / \mathrm{kg}$ BW were selected as a single or combination treatment for renal fibrosis in a mouse model of UUO.

To determine the potential toxicity of selected dosages of AA, NG, and their combination in vivo, we 
a. Dosage responses of $A A$
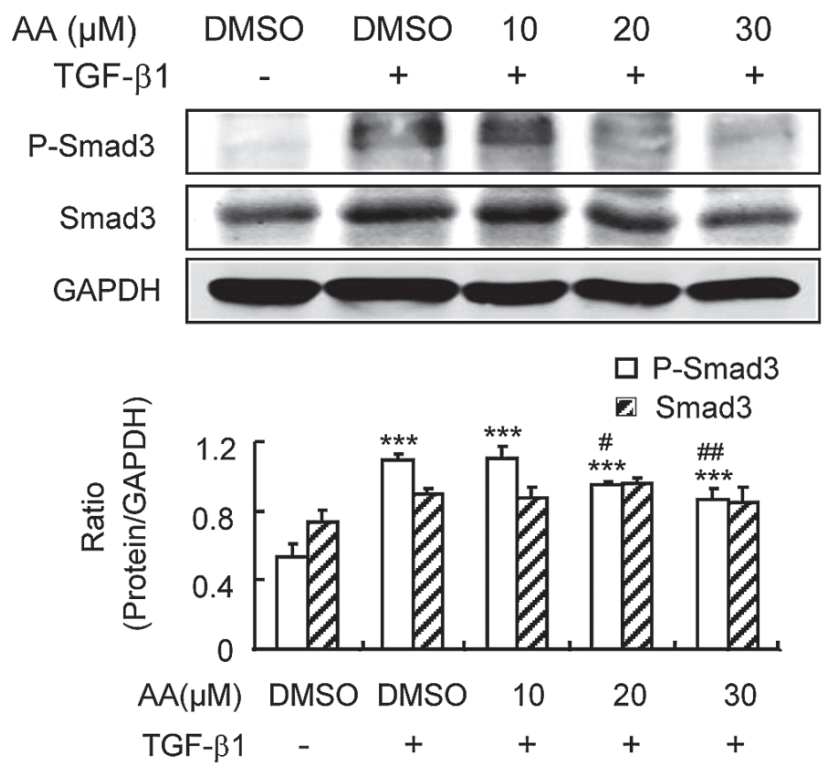

b. Dosage responses of $\mathrm{NG}$

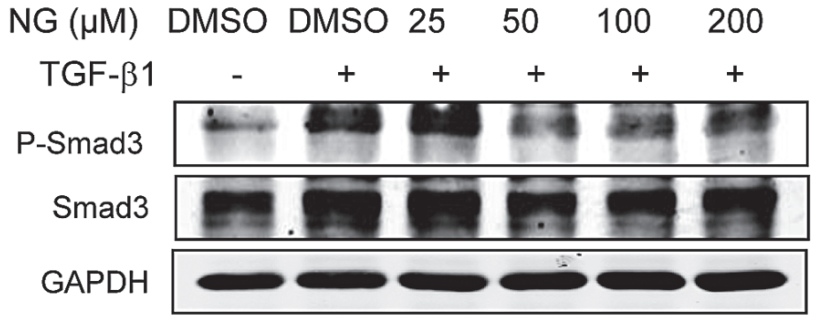

$\square$ P-Smad3

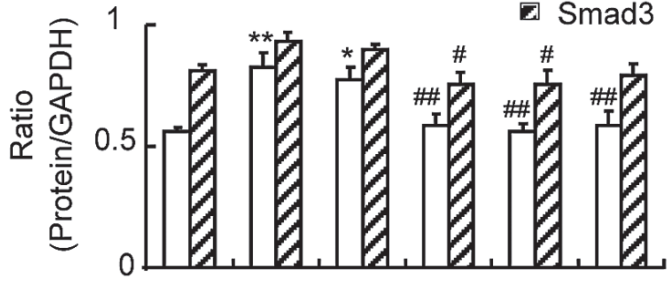

$\mathrm{NG}(\mu \mathrm{M})$ DMSO DMSO $25 \quad 50 \quad 100200$

TGF- $\beta 1$ - $\quad+\quad+\quad+\quad+\quad+$

C. Cytotoxicity assay

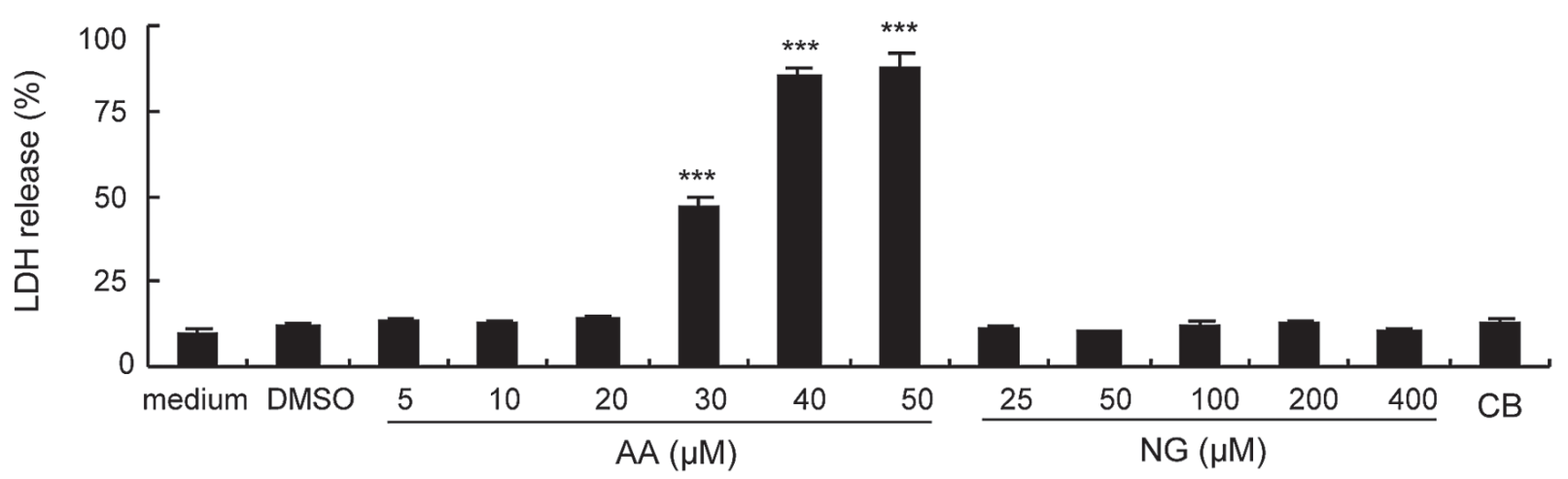

d. MTT assay

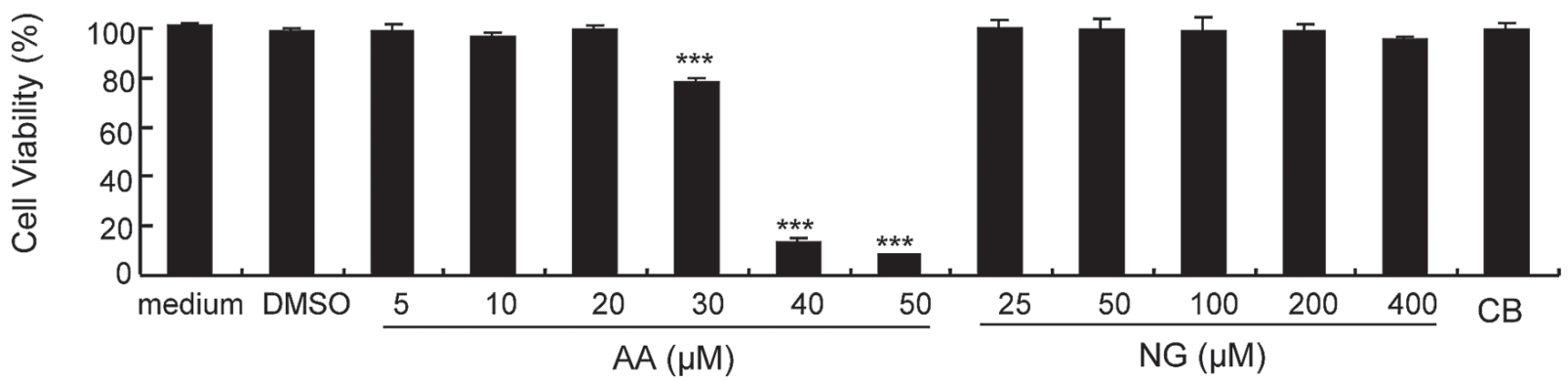

Figure 1: Dose-dependent effect of AA, NG, and their combination on inhibition of TGF- $\beta /$ Smad3 signaling and cytotoxicity in cultured TECs. a. Dose-dependent effect of AA on TGF- $\beta 1(2 \mathrm{ng} / \mathrm{ml})$-induced Smad3 phosphorylation and protein expression. b. Dose-dependent effect of AA on TGF- $\beta 1(2 \mathrm{ng} / \mathrm{ml})$-induced Smad3 phosphorylation and expression. . Dose-dependent effect of AA, NG and their combination on cytotoxicity as determined by the LDH release assay. Data represent the mean \pm SEM for at least 3 independent experiments. d. Dose-dependent effect of AA, NG and their combination on cytotoxicity as determined by the MTT assay. ${ }^{*} p$ $<0.05, p<0.01,{ }^{* * *} p<0.001$ compared to the DMSO control. ${ }^{\#} p<0.05,{ }^{\# \#} p<0.01$ compared to DMSO + TGF- $\beta 1$ treatment. 
treated groups of 4 normal mice with AA $(5 \mathrm{mg} / \mathrm{kg} \mathrm{BW})$, $\mathrm{NG}(50 \mathrm{mg} / \mathrm{kg} \mathrm{BW})$, and their combination for 7 days and collected serum for LDH release assay and 24-hour urine samples for measuring urinary albumin excretion. As shown in Figure 4c, serum levels of LDH and urinary albumin concentrations were not altered after treatment with $\mathrm{AA}, \mathrm{NG}$, and their combination. In addition, no histological abnormalities were noticed based on H\&E and PAS-staining (no shown).

We then determined the therapeutic efficacy of AA, $\mathrm{NG}$, and their combination in a mouse model of UUO as described above. Masson trichrome staining showed that single treatment with AA or NG significantly inhibited total collagen-like matrix deposition in the injured kidney, which was further improved by the combination treatment (Figure 5a and 5d). Immunohistochemistry also revealed that the combination treatment with AA and NG further decreased the accumulation of collagen I and $\alpha-\mathrm{SMA}^{+}$ myofibroblasts within the UUO kidney when compared with the individual treatment alone (Figure 5b, 5c, 5e, 5f). This was further confirmed at the mRNA levels by realtime PCR and at the total kidney protein levels by western

\section{a. Real-time PCR}

(i) Smad3 mRNA

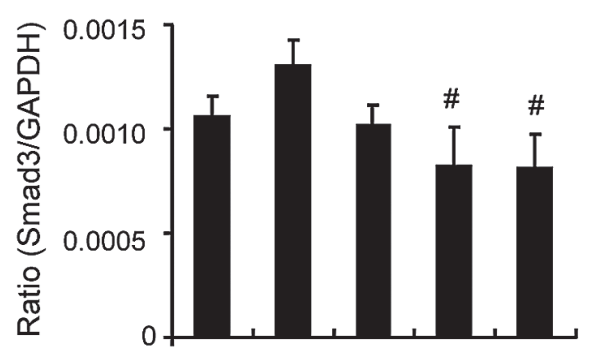

(ii) Smad7 mRNA

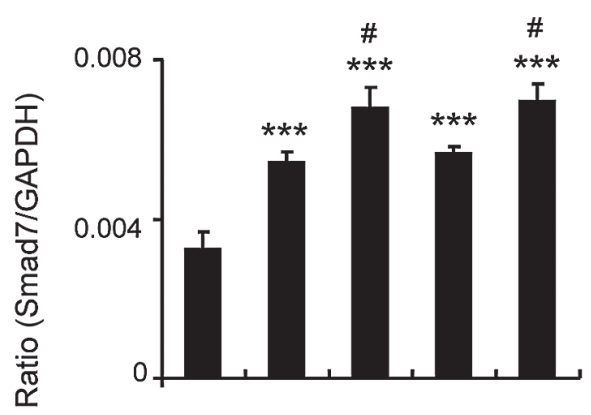

(iii) TGF- $\beta 1$ mRNA

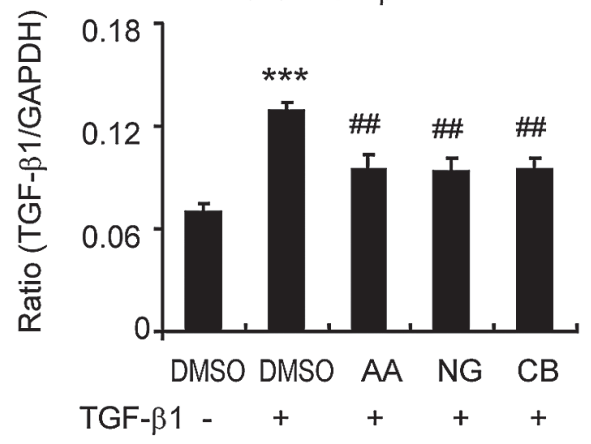

b. Western blot
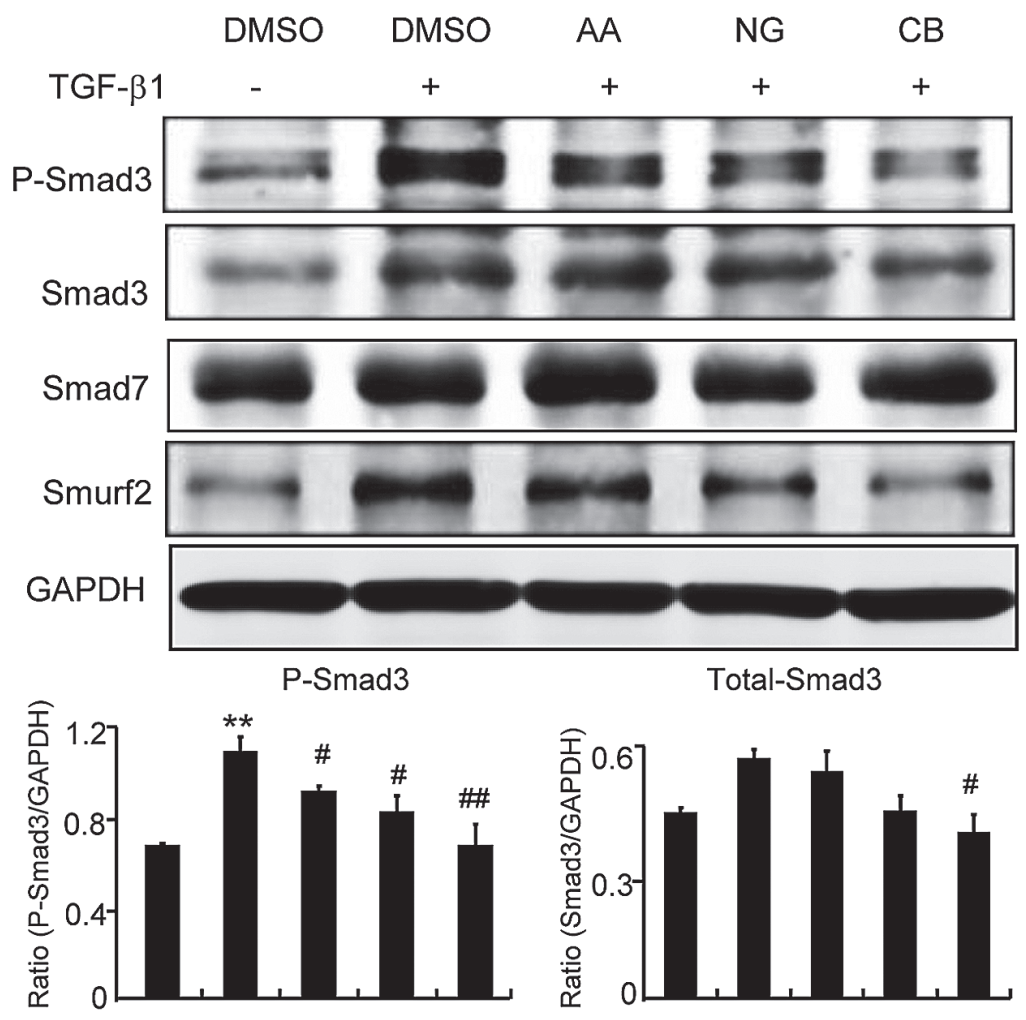

Smad7
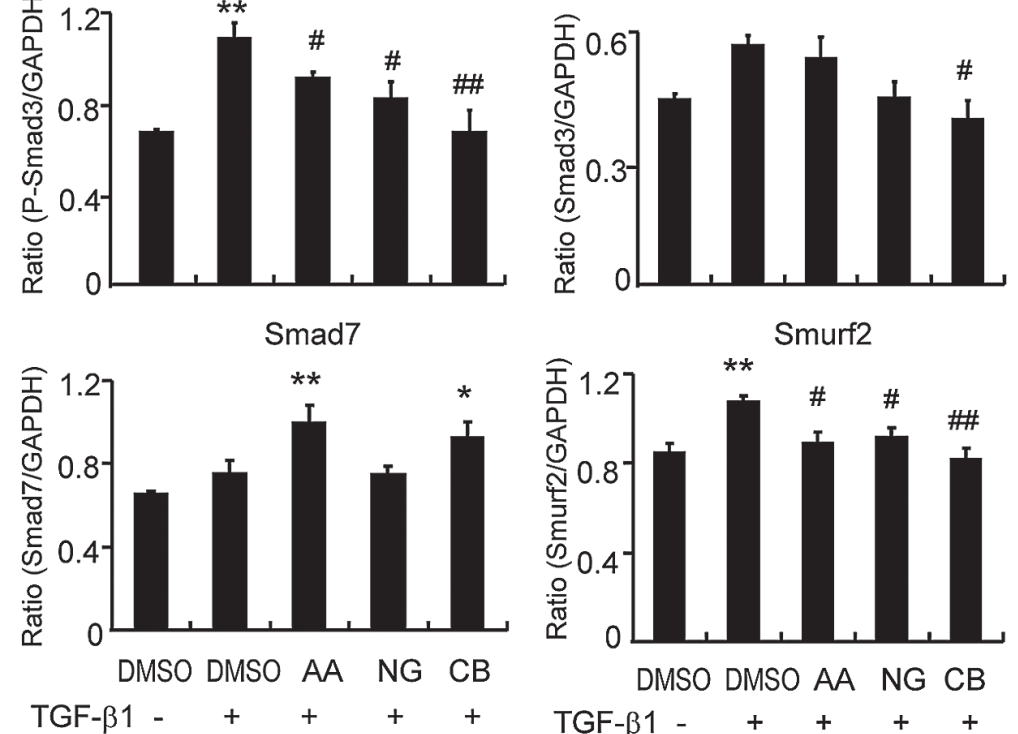

Figure 2: Combination of AA and NG produces an additive effect on inhibition of TGF- $\beta$ /Smad signaling via differential mechanisms in vitro. a. Effect of $\mathrm{AA}, \mathrm{NG}$, and their combination $(\mathrm{CB})$ on TGF- $\beta 1(2 \mathrm{ng} / \mathrm{ml})$-induced mRNA expression of Smad3, Smad7, and TGF- $\beta 1$ by real-time PCR. b. Effect of AA, NG, and their combination (CB) on TGF- $\beta 1(2 \mathrm{ng} / \mathrm{ml})$-induced protein levels of phospho-Smad3, Smad3, Smad7, and Smurf2 by Western blot analysis. Note that while AA inhibits phosphorylation of Smad3 by induction of Smad7, NG blocks Smad3 signaling by inhibiting Smad3 mRNA and protein expression. The combination of AA and NG additively inhibits TGF- $\beta / \mathrm{Smad} 3$ signaling. Data represent the mean $\pm \mathrm{SEM}$ for at least 3 independent experiments. ${ }^{*} p<0.05, p<0.01, * * * p<0.001$ compared to the DMSO control. ${ }^{\#} p<0.05,{ }^{\#} p<0.01$ compared to DMSO + TGF- $\beta 1$ treatment. 


\section{a. Real-time PCR}

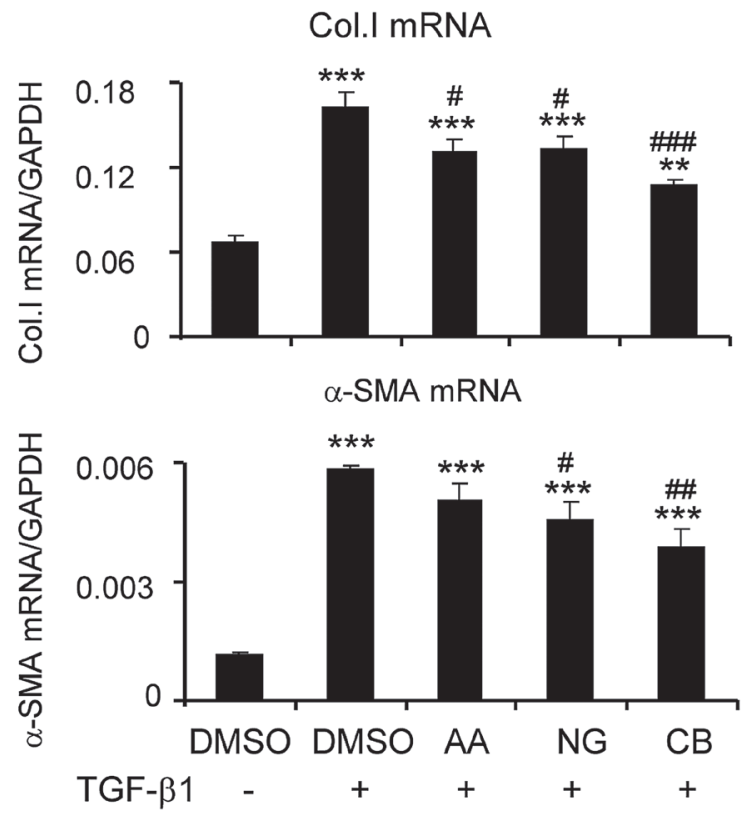

b. Western blot
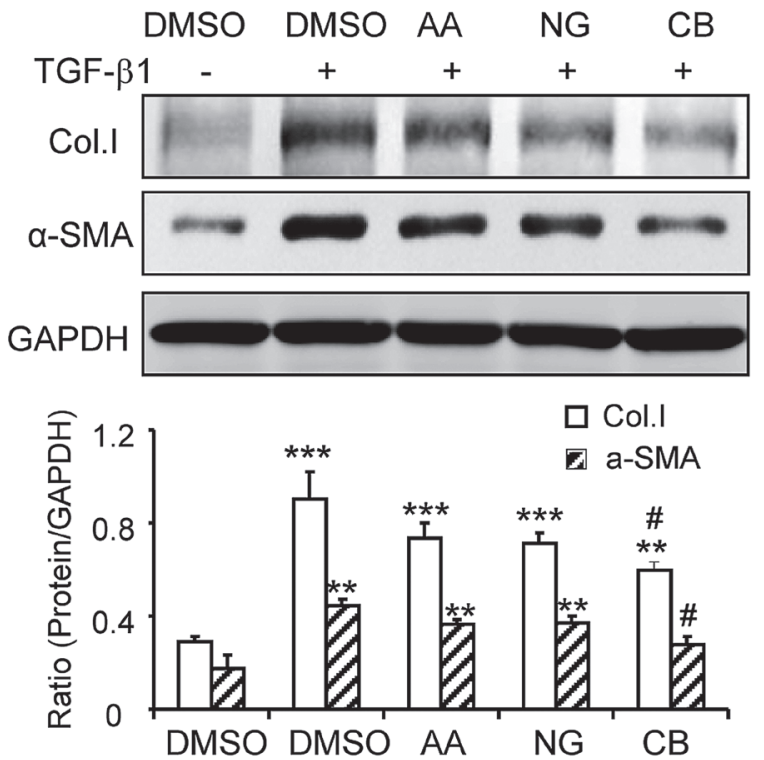

TGF- $\beta 1-\quad+\quad+\quad+\quad+$

Figure 3: Combination of AA and NG produces a better protective effect on TGF- $\beta 1$-induced fibrotic response in vitro. a. Effect of AA, NG, or their combination on TGF- $\beta 1$ ( $2 \mathrm{ng} / \mathrm{ml}$ )-induced mRNA expression of collagen I and $\alpha$-SMA detected by real-time PCR. $\mathbf{b}$. Effect of AA, NG, or their combination on TGF- $\beta 1(2 \mathrm{ng} / \mathrm{ml})$-induced mRNA expression of collagen I and $\alpha$-SMA detected by Western blot analysis. Data represent the mean \pm SEM for at least 3 independent experiments. ${ }^{* *} p<0.01,{ }^{* * *} p<0.001$ compared to the DMSO

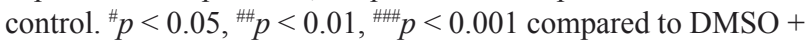
TGF- $\beta 1$ treatment. a. Dosage responses of $A A$ in renal fibrosis

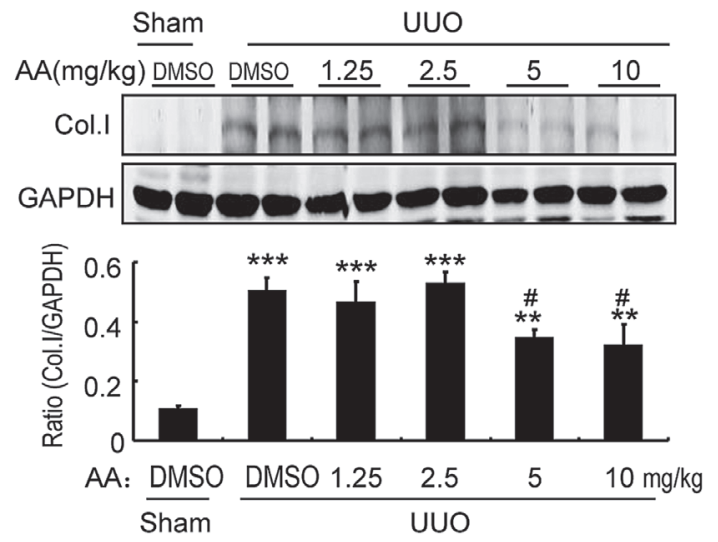

b. Dosage responses of NG in renal fibrosis
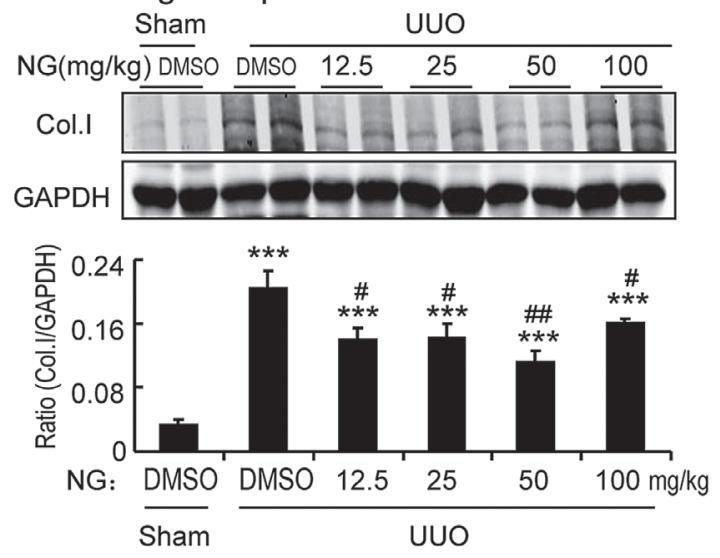

c. In vivo toxicity assay

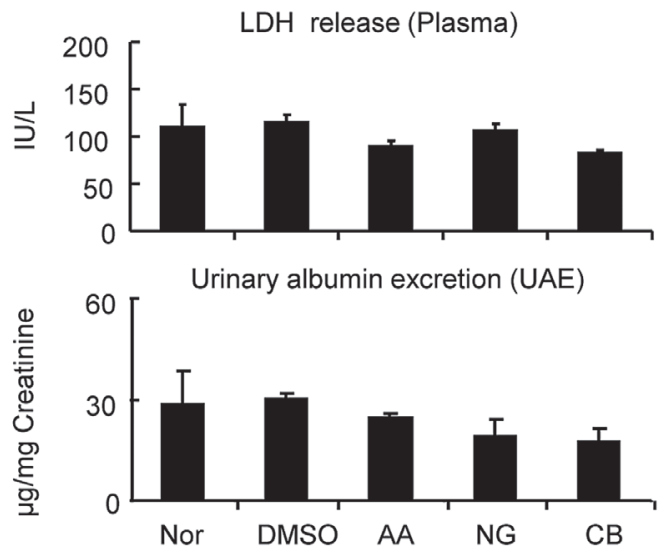

Figure 4: Dose-dependent effect of AA, NG, and their combination on inhibition of renal fibrosis in a mouse model of UUO. a. Dose-dependent responses of AA in inhibition of collagen I expression by Western blot analysis. b. Dose-dependent responses of NG in inhibition of collagen I expression by Western blot analysis. c. LDH release assay for determination of the toxicity of AA $(5 \mathrm{mg} / \mathrm{kg}), \mathrm{NG}(50 \mathrm{mg} /$ $\mathrm{kg}$ ), and their combination in groups of 4 normal mice. Data represent the mean \pm SEM for groups of 4 mice. ${ }^{* *} p<0.01$, ${ }^{* * *} p<0.001$ compared to sham-operated mice. ${ }^{*} p<0.05,{ }^{*} p<<$ 0.01 compared to DMSO-treated UUO mice. 
blot analysis (Figure 6).

\section{Mechanisms of AA, NG, and their combination treatment in renal fibrosis in vivo}

We next examined the mechanisms of $\mathrm{AA}, \mathrm{NG}$, and their combination in anti-renal fibrosis. As shown in Figures 7 and 8, treatment with AA or NG alone partially inhibited upregulation of TGF- $\beta 1$ and phosphorylation of Smad3 and phospho-Smad3 nuclear translocation, which was further suppressed by the combination of AA and NG. Consistent with the findings in vitro, the inhibitory effect of AA on Smad3 signaling in the UUO kidney was correlated with a significant upregulation of renal Smad7 at both mRNA and protein levels without altering Smad3 mRNA and protein expression (Figure 7). In contrast, blockade of Smad3 signaling with NG was associated with downregulation of Smad3 at both mRNA ad protein levels without altering Smad7 mRNA and protein levels (Figure 7). The combination treatment with AA and NG produced a better inhibitory effect on TGF- $\beta /$ Smad signaling by

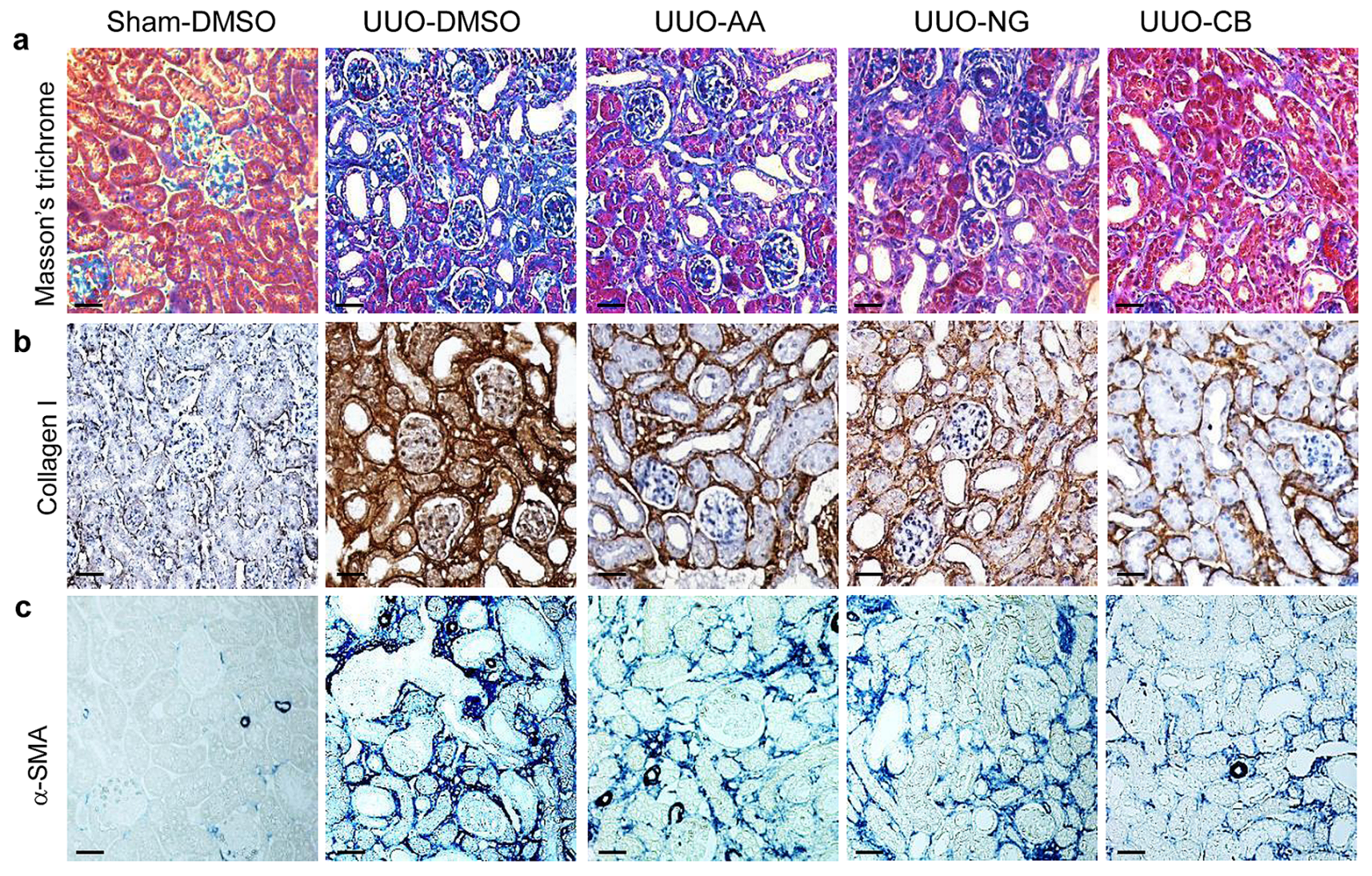

d

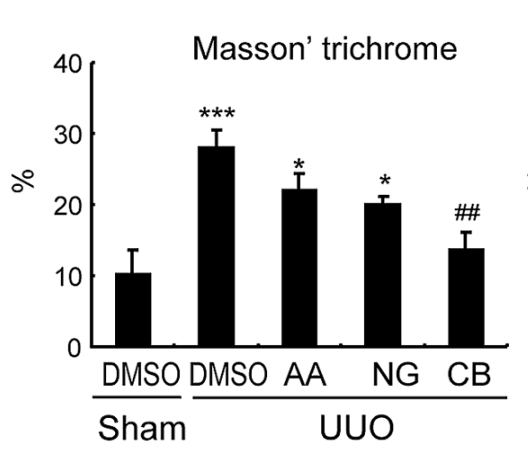

e

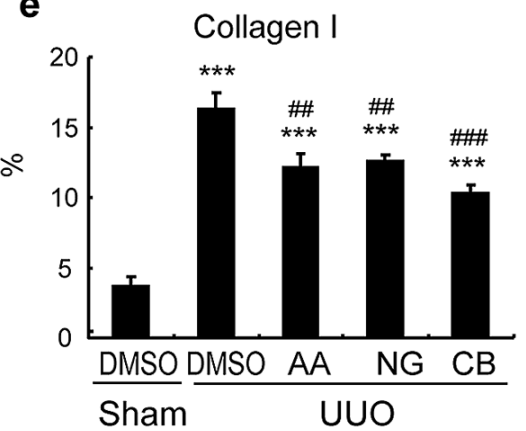

f

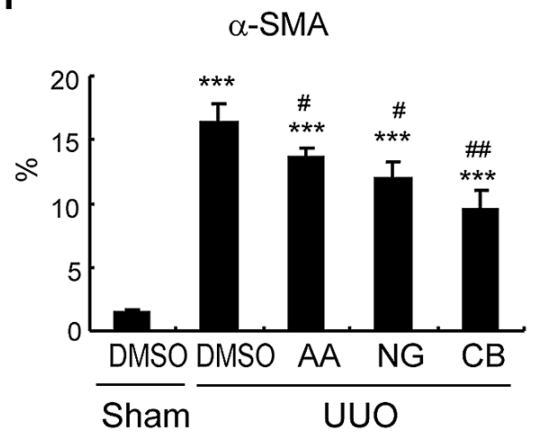

Figure 5: Histologic and immunohistochemical examination show that the combination treatment with AA and NG produces a better inhibitory effect on renal fibrosis in a mouse model of UUO. a. Masson's trichrome staining. b. Immunohistochemical staining of collagen I. c. Immunohistochemical staining of $\alpha$-SMA. d. Quantitative analysis of Masson trichrome staining. e. Quantitative analysis of collagen I immunostaining. f. Quantitative analysis of $\alpha$-SMA Immunostaining. Data represent the mean \pm SEM for groups of 6-8 mice. ${ }^{*} p<0.05,{ }^{* * *} p<0.001$ compared to sham-operated mice. ${ }^{*} p<0.05,{ }^{*} p<0.01$ compared to DMSOtreated UUO mice. Scale bars, $50 \mu \mathrm{M}$. 
further suppressing Smad3 signaling while inducing Smad7 mRNA expression as well as preventing Smad7 protein from degradation by decreasing Smurf2 (Figure $7 a, 7 b)$.

Consistent with our previous finding that there was a markedly upregulation of miR-21 but downregulation of miR-29b in the UUO kidney [38, 39]. Interestingly, treatment with either AA or NG significantly reduced miR-21 expression, which was further suppressed when animals were treated with the combination of AA and NG (Figure 8b). A similar result was also found in the cultured TECs in which the combination treatment with AA and $\mathrm{NG}$ resulted in further inhibition of miR-21 expression (Figure 8c). However, treatment with AA, NG or the combination did not alter the expression of miR-29b in the UUO kidney and in vitro (Figure 8d).

\section{a. Real-time PCR}
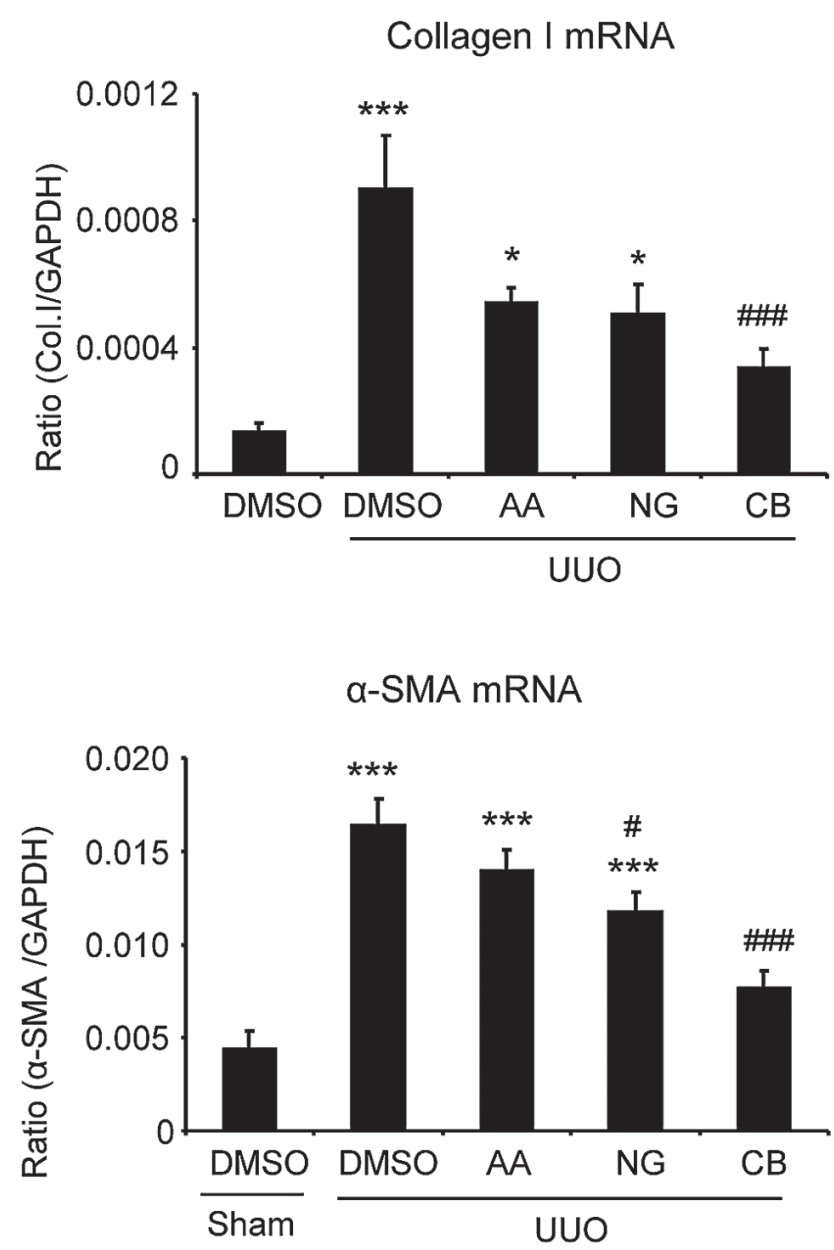

\section{DISCUSSION}

Increasing evidence shows that TGF- $\beta 1 / \mathrm{Smad}$ signaling is a central pathway leading to tissue fibrosis $[1,2]$. It is now clear that Smad3 is a key fibrogenic mediator and is highly activated during renal fibrosis. In contrast, Smad7, an inhibitor of TGF- $\beta /$ Smad3 signaling, is lost in the scarring kidney [2]. In the present study, we identified that AA, a purified compound from Centella asiatica [20], is a Smad7 agonist, whereas NG, a flavonoid from grapefruit and citrus fruits [28], functioned as a Smad3 inhibitor. The combination of these two purified Traditional Chinese Medicine compounds significantly enhanced the inhibitory effect on TGF- $\beta /$ Smad signaling and renal fibrosis in vitro and in vivo. Outcomes from this study suggested that restoring the balance of downstream TGF- $\beta$ /Smad signaling with AA (a Smad7 agonist) and $\mathrm{NG}$ (a Smad3 inhibitor) may represent a new therapeutic

\section{b. Western blot analysis}

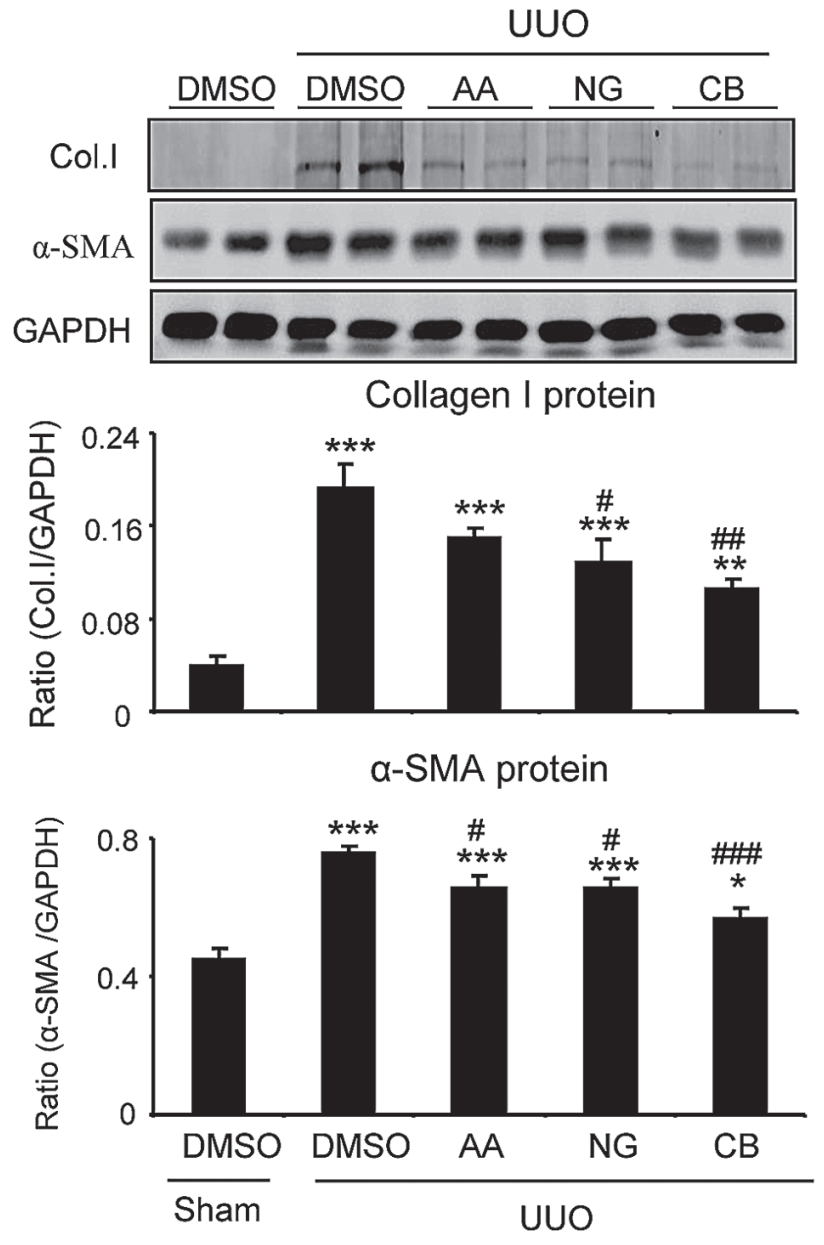

Figure 6: Real-time PCR and Western blot analysis detect that the combination treatment with AA and NG produces a better inhibitory effect on renal fibrosis in a mouse model of UUO. a. Collagen I and $\alpha$-SMA mRNA expression by realtime PCR. b. Collagen I and $\alpha$-SMA protein expression by Western blotting. Results show that the combination of AA and NG treatment produces an additive effect on inhibition of collagen I and $\alpha$-SMA expression. Data represent the mean SEM for groups of 6-8 mice. * $p<$ $0.05,{ }^{*} p<0.01,{ }^{* * *} p<0.001$ compared to sham-operated mice. ${ }^{\#} p<0.05,{ }^{\# \#} p<0.01,{ }^{\# \# \#} p<0.001$ compared to DMSO-treated UUO mice. 


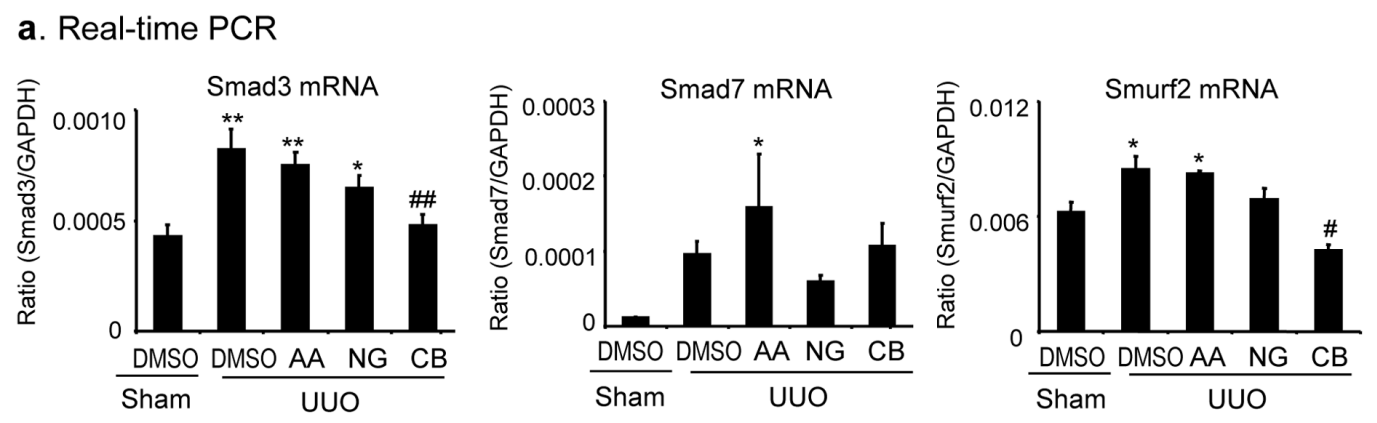

b. Western blot
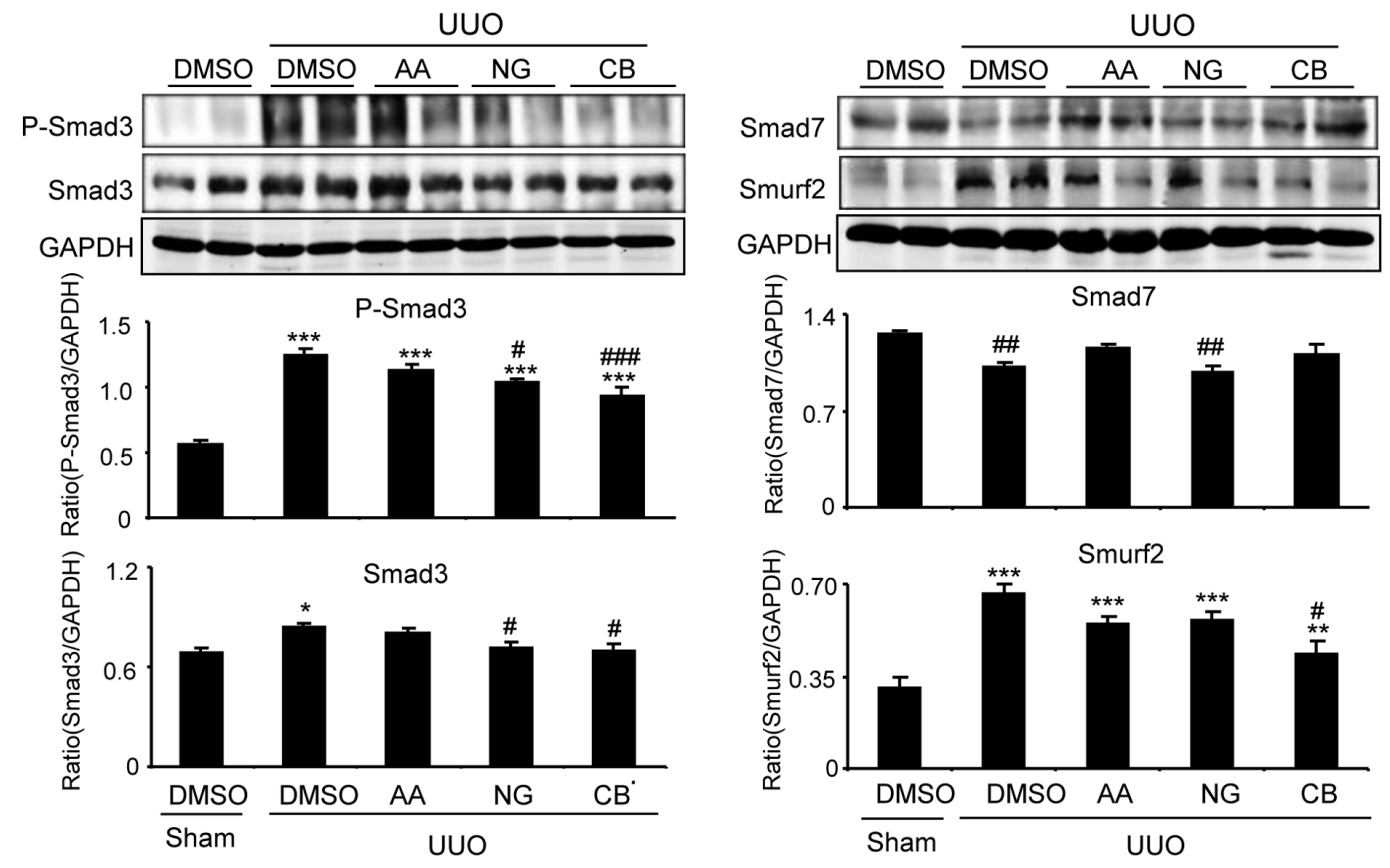

C. Immunohistochemistry
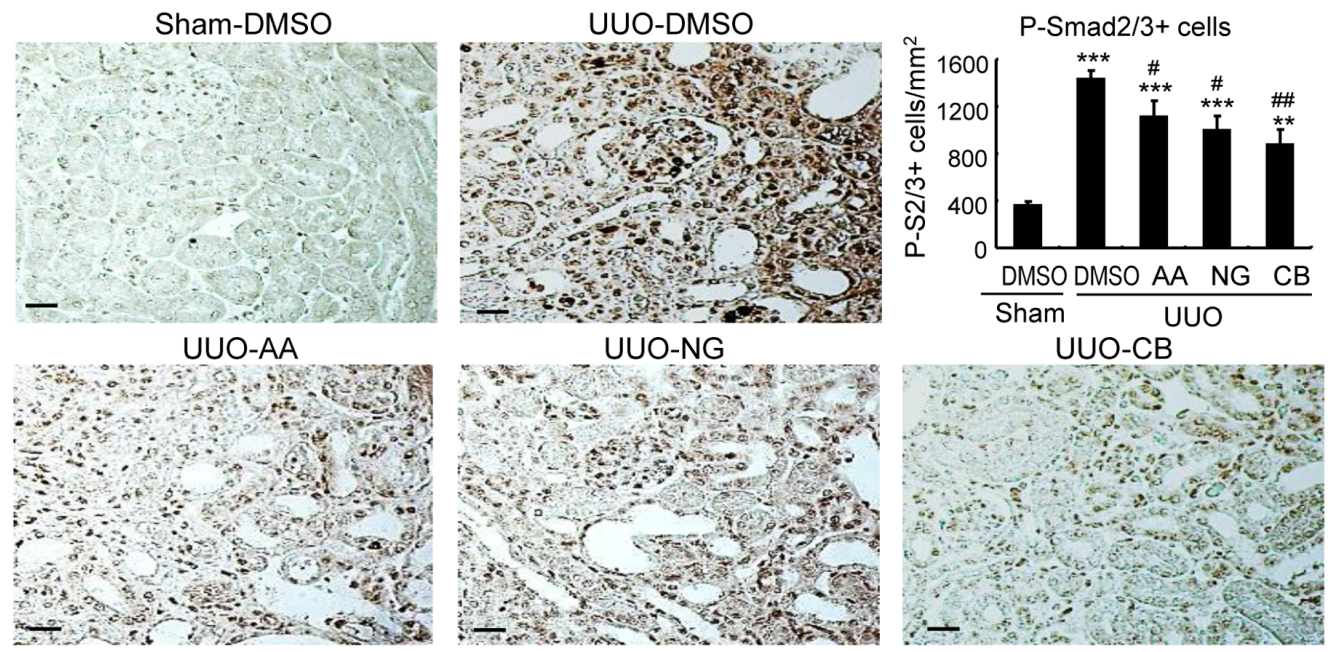

Figure 7: Combination treatment with AA and NG results in a further inhibition of TGF- $\beta /$ Smad signaling in the UUO kidney. a. Inhibitory effect of AA, NG, and their combination (CB) on Smad3, Smad7, and Smurf2 mRNA expression by real-time PCR. b. Western blot analysis shows the inhibitory effect of AA, NG, and their combination (CB) on phosphorylation levels of Smad3 and total protein levels of Smad3, Smad7, and Smurf2 in the UUO kidney. c. Immunohistochemistry shows the inhibitory effect of AA, NG, and their combination (CB) on phospho-Smad3 nuclear translocation in the UUO kidney. Note that while AA inhibits phosphorylation of Smad3 by induction of Smad7, NG blocks Smad3 signaling by inhibiting Smad3 mRNA and protein expression. The combination of AA and NG additively inhibits Smurf2 and TGF-/Smad3 signaling. Data represent the mean \pm SEM for groups of 6-8mice. ${ }^{*} p<0.05, * * p<0.01,{ }^{* * *} p$ $<0.001$ compared to sham-operated mice. ${ }^{\#} p<0.05,{ }^{\# \#} p<0.01$ compared to DMSO-treated UUO mice. Scale bars, $50 \mu \mathrm{M}$. 
a. TGF- $\beta 1$ expression in the UUO kidney
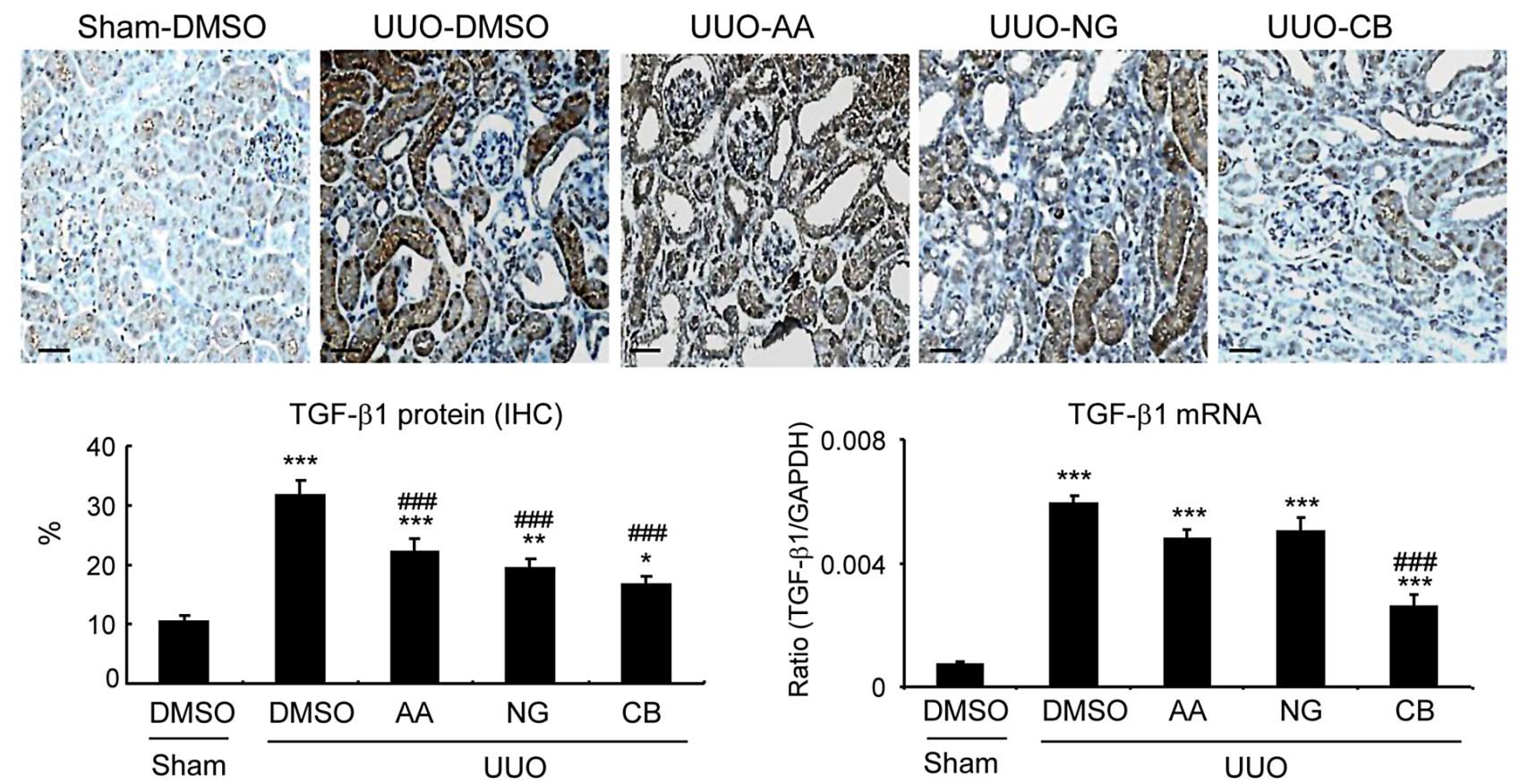

b. miR-21 expression in the UUO kidney

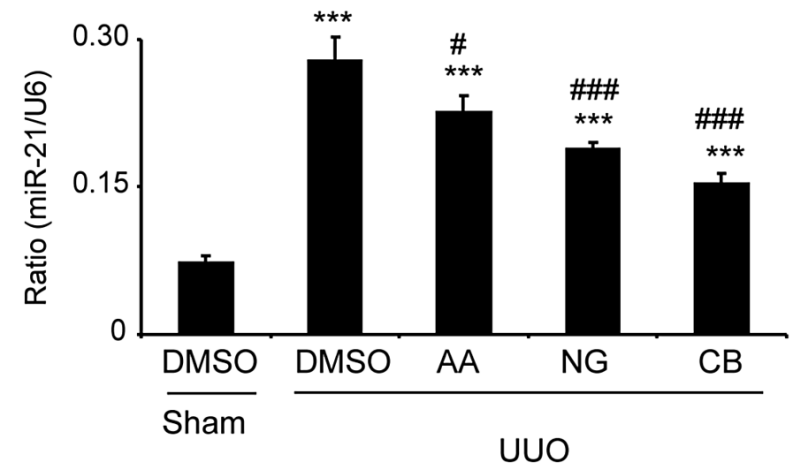

C. miR-21 expression in vitro

d. miR-29 expression in the UUO kidney
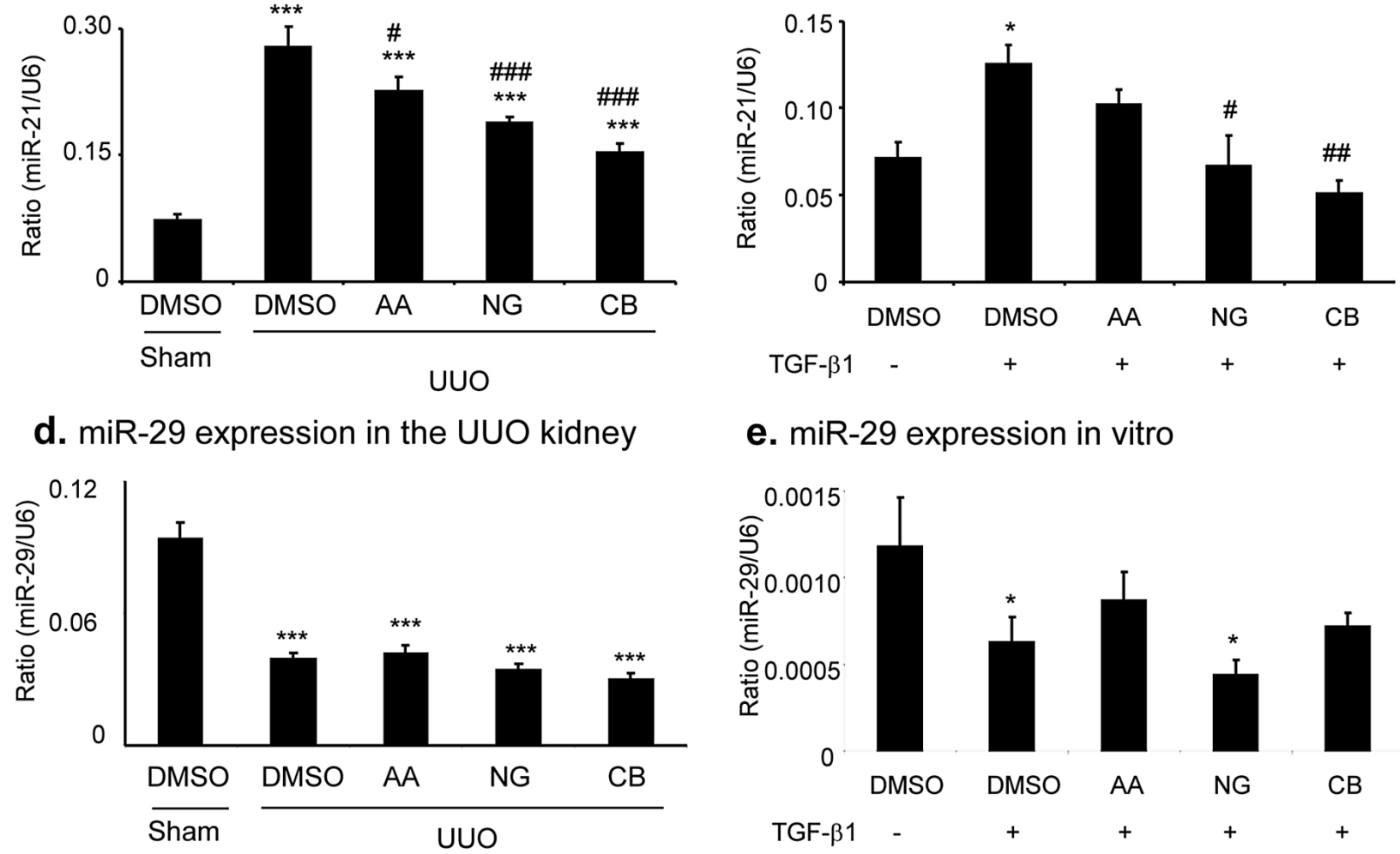

e. miR-29 expression in vitro

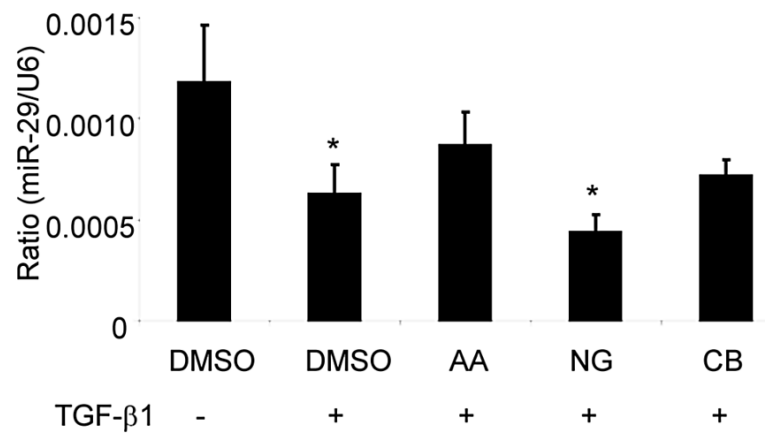

Figure 8: Combination treatment with AA and NG produces a further suppressive effect on renal TGF- $\beta 1$ and miR21 expression in the UUO kidney. a. Immunohistochemistry and real-time PCR show the inhibitory effect of AA, NG, and their combination (CB) on TGF- $\beta 1$ expression in the UUO kidney. b., c. Real-time PCR detects that the combination treatment with AA and NG results in a further suppression of miR-21 expression in the UUO kidney and in cultured TECs. d., e. Real-time PCR detects miR-29b expression in the UUO kidney and in cultured TECs. Data represent the mean \pm SEM for groups of 6-8 mice. ${ }^{*} p<0.05,{ }^{* *} p<0.01,{ }^{* * *} p$ $<0.001$ compared to sham-operated mice. ${ }^{*} p<0.05,{ }^{\# \#} p<0.01$ compared to DMSO-treated UUO mice. Scale bars, $50 \mu \mathrm{M}$. 
approach for chronic kidney disease associated with progressive renal fibrosis.

The identification of NG as a Smad3 inhibitor and $\mathrm{AA}$ as a Smad7 agonist was an important finding in the present study. Consistent with the consensus that Smad3 stimulates tissue fibrosis in a number of chronic kidney diseases [12, 13], inhibition of $\operatorname{Smad} 3$ transcription and phosphorylation was a mechanism through which NG inhibits fibrosis in vitro and in vivo. This finding was consistent with other studies in which inhibition of Smad3 with SIS3 (a Smad3 inhibitor to block Smad3 DNA binding and phosphorylation) and GQ5 (a small compound isolated from the dried resin of Toxicodendron vernicifluum that blocks the binding of Smad3 to TGF- $\beta$ type I receptor) attenuates renal fibrosis [30, 31]. Interestingly, addition of NG blocks Smad3 mRNA and protein expression without altering levels of Smad7 expression, indicating a specific effect of $\mathrm{NG}$ on inhibiting Smad3 without influencing Smad7. In the present study, we also found that addition of AA was capable of blocking Smad3 phosphorylation and renal fibrosis by upregulating Smad7 without altering expression of Smad3, identifying AA as a Smad7 agonist to inhibit Smad3 signaling by inducing Smad7 transcription. This finding was consistent with our previous study that treatment with AA inhibits liver fibrosis by inducing Smad7 [23]. It is well accepted that Smad7 is an inhibitor of Smad3 signaling and protects against tissue fibrosis in a number of diseases [17, 32-35]. However, Smad7 is lost in the fibrosing tissue, which is induced by Smurf2, an E3 ligase that targets Smad7 for ubiquitin degradation $[36,37]$. It is reported that TGF- $\beta 1$ induces Smurf2 expression via a Smad3-dependent mechanism [37]. Thus, the combination treatment with AA and NG produced a better inhibitory effect on Smad3 signaling via direct and indirect mechanisms.

We have previously shown that TGF- $\beta /$ Smad 3 mediates renal fibrosis by upregulating miR-21 but downregulating miR-29b in the UUO and diabetic nephropathy [38-41]. In the present study, we found that treatment with $\mathrm{AA}$ or $\mathrm{NG}$ also produced an additive effect on inhibition of miR-21 expression. However, treatment with AA and NG did not alter the expression of miR-29b in vivo and in vitro. Thus, inhibition of miR-21 expression may also account for a mechanism whereby AA, NG, and their combination treatment inhibited renal fibrosis.

The combination of AA and NG also allowed using lower dosages of AA and NG, which prevented the drug cytotoxicity while enhancing the therapeutic efficacy on renal fibrosis. Indeed, a single use of AA or NG induced an inhibition of Smad3 signaling in a dosage-dependent manner; however, it also caused the anti-proliferation effect and cytotoxicity when higher dosages were used. The combination of AA and NG allowed lowering the dosages of individual drugs to produce a safer but effective therapy for renal fibrosis without cytotoxicity. This is important since the cytotoxicity has been a major problem for the clinical application of the Traditional Chinese Medicine [42].

In summary, the present study demonstrates that AA functions as a Smad7 agonist and inhibits Smad3 signaling by inducing Smad7; whereas NG is a Smad3 inhibitor and blocks Smad3 signaling directly by inhibiting Smad3 phosphorylation and transcription. Thus, the combination of AA and NG produces an additive effect on inhibition of renal fibrosis by inhibiting Smad3 while upregulating Smad7 and may represent as a novel and effective therapy for chronic kidney disease including diabetic and hypertensive nephropathy.

\section{MATERIALS AND METHODS}

\section{A mouse model of UUO and treatment}

A mouse model of UUO was established in C57BL6 male mice (6 weeks of age, 20-22g) by ligating the left ureter as previously described [11]. Animals were randomly divided into 5 groups including Sham, UUO with vehicle control (DMSO) or treated with $\mathrm{AA}, \mathrm{NG}$, and the combination of AA plus NG. AA was a HLPC-purified product $(95 \%)$ purchased from Guangxi Changzhou Natural Pharmaceutical Co. Ltd (Nanning, Guangxi, China). NG was obtained from Shanxi Huike Botanical Development Co. Ltd (Xian, Shanxi, China) with the HLPC-purity of $98 \%$. Either AA or NG was dissolved in $1 \%$ DMSO and was administrated into mouse daily via intraperitoneal (i.p) injection. Briefly, after UUO surgery, groups of 8 mice were housed in the Animal Facility of Chinese University of Hong Kong (CUHK) with a 12/12hour light/dark cycle and food and water available and received daily i.p. injections of control saline containing $1 \%$ DMSO, an optimal dose of AA at $5 \mathrm{mg} / \mathrm{kg} /$ boy weight (BW) and NG at $50 \mathrm{mg} / \mathrm{kg} / \mathrm{BW}$, or the combination of AA $(5 \mathrm{mg} / \mathrm{kg} / \mathrm{BW})$ plus NG $(50 \mathrm{mg} / \mathrm{kg} / \mathrm{BW})$ for seven days. Kidney tissues were harvested and examined for renal fibrosis. The experimental procedures were approved by the Animal Ethics Committee of The CUHK.

\section{Determination of an optimal dose of $\mathrm{AA}, \mathrm{NG}$, and their combination ratio in vitro and in vivo}

We first determined an optimal dosage of AA, $\mathrm{NG}$, and their combination with the maximal inhibitory effect on TGF- $\beta 1 /$ Smad signaling without cytotoxicity in vitro and in vivo. In vitro, a normal rat kidney tubular epithelial cell line (NRK52E) were cultured in Dulbecco's modified Eagle's medium (DMEM)-F12 medium supplemented with 5\% fetal bovine serum (FBS). After being fasted, cells were incubated with AA (dissolved in $1 \%$ DMSO) at dosages of $0,5,10,20,30,40,50 \mu \mathrm{M}$ and NG at dosages of $0,25,50,100,200,400 \mu \mathrm{M}$ for 
24 hours. The supernatant from individual treatments was then collected for testing the cytotoxicity by the lactate dehydrogenase (LDH) releasing assay with a LDH release kit (BioVision Technologies, Exton, PA, USA) following the manufacturer's instructions. After determining safe dosages of AA and NG, a dose-dependent inhibitory effect of AA and NG on TGF- $\beta /$ Smad signaling was performed in NRK52E cells with addition of a recombinant human TGF- $\beta 1$ ( 2 ng/ml; R\&D Systems, Minneapolis, MN, USA) for periods of $0,30 \mathrm{~min}, 3 \mathrm{~h}, 6 \mathrm{~h}$, and $24 \mathrm{~h}$ following the 24 hour pre-incubation with the safe dosages of AA or NG. At least three-independent experiments were performed and $1 \%$ DMSO was used as control for all studies. Then, a safe and effective dose of AA and NG was selected for in vitro study.

Effective dosages of AA and NG for renal fibrosis were determined in groups of 4 mice with UUO by daily i.p injection of AA at dosages of $1.25,2.5,5.0$, and 10 $\mathrm{mg} / \mathrm{kg}$ body weight or $\mathrm{NG}$ at dosages of $12.5,25,50$, and $100 \mathrm{mg} / \mathrm{kg}$ body weight for 7 days. A dose-dependent inhibitory effect of AA and NG on renal fibrosis was determined by western blot analysis of collagen I expression. After selecting an effective dosage for AA and $\mathrm{NG}$, we performed a toxicity test in vivo in groups of 4 normal mice by a daily i.p. injection of DMSO, AA (5mg/kg BW), NG (50mg/kg BW), and their combination AA $(5 \mathrm{mg} / \mathrm{kg} / \mathrm{BW})$ plus $\mathrm{NG}(50 \mathrm{mg} / \mathrm{kg} / \mathrm{BW})$ for 7 days, respectively. Blood plasma was collected at day 7 after the treatment for the LDH releasing assay and 24-hour urinary samples were collected in the metabolism cages. Urinary albumin excretion (UAE) assay was performed by using competitive ELISA according to the manufacturer's instructions (Exocell, Philadelphia, PA, USA).

\section{Masson's trichrome staining and Immunohistochemistry}

To evaluate the histological damage, collagenlike matrix deposition was stained with Masson's trichrome staining with the 'Trichrome stain kit' (Scy Tek Laboratoris, West Logan, UT) according to the manufacturer's instruction. Immunohistochemistry for detection of TGF- $\beta /$ Smad signaling and renal fibrosis was performed in $4 \mu \mathrm{m}$ paraffin-embedded tissue sections of mouse kidney tissue using a microwave-based antigen retrieval technique [43]. Primary antibodies used in this study included rabbit polyclonal antibodies to TGF- $\beta 1$, phosphorylated Smad2/3 (Santa Cruz Biotechnology, Santa Cruz, CA), collagen I (Southern Biotech, Birmingham, AL), $\alpha$-SMA (Sigma, St. Louis, MO). The number of phospho-Smad2/3 was counted under highpower fields $(\times 40)$ by means of a $0.0625-\mathrm{mm}^{2}$ graticule fitted in the eyepiece of the microscope and expressed as cells per millimeters squared. The total collagen-like contents, expression of TGF- $\beta 1$, and accumulation of collagen I and $\alpha$-SMA on were measured in Masson's trichrome and immunostained sections by 10 random areas under high-power by using a quantitative image-analysis system (Image-Pro Plus 6.5, Media Cybernetics, Silver Spring, MD) and expressed as the percent positive area examined.

\section{RNA extraction and real-time PCR}

Total RNA was isolated from kidney tissues and cultured cells using the RNeasy Isolation Kit (Qiagen, Valencia, CA) according to the manufacturer's instructions. Real-time PCR was performed using the BioRad iQ SYBR Green supermix with Opticon2 (Bio-Rad, Hercules, CA) as previously described [16]. The primers used in the current study including mouse collagen I, $\alpha$-SMA, TGF- $\beta 1$, Smad7, Smurf2 and glyceraldehyde 3 -phosphate dehydrogenase (GAPDH) were described previously $[35,44]$. In addition, expression of miR-21 and miR-29b expression in cultured TECs and in the UUO kidney was measured by real-time PCR with primers as previously described $[38,39]$. The ratio for the mRNA of interest was normalized to GAPDH and expressed as the mean \pm standard errors of the mean (SEM).

\section{Western blot analysis}

Proteins from kidney tissues and cultured cells were extracted with RIPA lysis buffer, and western blot analysis was performed as described previously [10]. After blocking the nonspecific binding with 5\% BSA (1h, room temperature), membranes were then incubated with the primary antibody against phospho-Smad3 (Cell Signaling Technology), collagen I (Southern Biotech), Smad7, Smurf2, total Smad3 (Santa Cruz Biotechnology), a-SMA, glyceraldehyde 3-phosphate dehydrogenase (Chemicon, Temecula, CA) overnight at $4^{\circ} \mathrm{C}$, followed by the IRDye 800-conjugated secondary antibody (Rockland immunochemicals, Gilbertsville, PA). Signals were captured using the LiCor/Odyssey infrared image system (LI-COR Biosciences, Lincoln, NE) and the intensity of each band was quantified and analyzed by using the Image J software (NIH, Bethesda, MD, USA).

\section{Urinary albumin excretion}

To determine the potential toxicity to the kidney, 24hour urinary samples from groups of 4 normal mice were collected in the metabolic cages after treatment with AA, $\mathrm{NG}$, and their combination for 7 days. Urinary albumin excretion was measured by competitive ELISA according to the manufacturer's instructions (Exocell, PA). Urinary creatinine was measured by an enzymatic kit (Stanbio Labs, TX). Urinary albumin excretion was expressed as 
total urinary albumin/creatinine ratio.

\section{Statistical analyses}

Data are expressed as the mean \pm SEM and analyzed using one-way analysis of variance (ANOVA), followed by Tukey post-hoc tests using GraphPad Prism 5 (GraphPad Software, San Diego, CA).

\section{ACKNOWLEDGMENTS}

This study was supported by a Major State Basic Research Development Program of China (973 program, No.2012CB517705), the Research Grants Council of Hong Kong (GRF 468711, CUHK3/CRF/12R), the Focused Investment Scheme A from Chinese University of Hong Kong, and the National Natural Science Foundation of China (No. 81300580, No. 81570623).

\section{CONFLICTS OF INTEREST}

All authors declare no conflict of interest.

\section{REFERENCES}

1. Meng XM, Tang PM, Li J and Lan HY. TGF-beta/Smad signaling in renal fibrosis. Frontiers in physiology. 2015: 82.

2. Meng XM, Chung AC and Lan HY. Role of the TGF-beta/ BMP-7/Smad pathways in renal diseases. Clin Sci (Lond). 2013; 4: 243-254.

3. Bottinger EP. TGF-beta in renal injury and disease. Seminars in nephrology. 2007; 3: 309-320.

4. Gewin L and Zent R. How does TGF-beta mediate tubulointerstitial fibrosis? Seminars in nephrology. 2012; 3: $228-235$.

5. Lopez-Hernandez FJ and Lopez-Novoa JM. Role of TGFbeta in chronic kidney disease: an integration of tubular, glomerular and vascular effects. Cell and tissue research. 2012; 1: 141-154.

6. Border WA and Noble NA. Evidence that TGF-beta should be a therapeutic target in diabetic nephropathy. Kidney international. 1998; 4: 1390-1391.

7. Moon JA, Kim HT, Cho IS, Sheen YY and Kim DK. IN-1130, a novel transforming growth factor-beta type I receptor kinase (ALK5) inhibitor, suppresses renal fibrosis in obstructive nephropathy. Kidney international. 2006; 7: 1234-1243.

8. Petersen $M$, Thorikay $M$, Deckers $M$, van Dinther $M$, Grygielko ET, Gellibert F, de Gouville AC, Huet S, ten Dijke P and Laping NJ. Oral administration of GW788388, an inhibitor of TGF-beta type I and II receptor kinases, decreases renal fibrosis. Kidney international. 2008; 6: 705715 .
9. Ma LJ, Jha S, Ling H, Pozzi A, Ledbetter S and Fogo AB. Divergent effects of low versus high dose anti-TGF-beta antibody in puromycin aminonucleoside nephropathy in rats. Kidney international. 2004; 1: 106-115.

10. Meng XM, Huang XR, Xiao J, Chen HY, Zhong X, Chung $\mathrm{AC}$ and Lan HY. Diverse roles of TGF-beta receptor II in renal fibrosis and inflammation in vivo and in vitro. The Journal of pathology. 2012; 2: 175-188.

11. Meng XM, Huang XR, Chung AC, Qin W, Shao X, Igarashi $\mathrm{P}, \mathrm{Ju} \mathrm{W}$, Bottinger EP and Lan HY. Smad2 protects against TGF-beta/Smad3-mediated renal fibrosis. Journal of the American Society of Nephrology : JASN. 2010; 9: 14771487.

12. Sato M, Muragaki Y, Saika S, Roberts AB and Ooshima A. Targeted disruption of TGF-beta1/Smad3 signaling protects against renal tubulointerstitial fibrosis induced by unilateral ureteral obstruction. The Journal of clinical investigation. 2003; 10: 1486-1494.

13. Inazaki K, Kanamaru Y, Kojima Y, Sueyoshi N, Okumura K, Kaneko K, Yamashiro Y, Ogawa H and Nakao A. Smad3 deficiency attenuates renal fibrosis, inflammation, and apoptosis after unilateral ureteral obstruction. Kidney international. 2004; 2: 597-604.

14. Liu Z, Huang XR and Lan HY. Smad3 mediates ANG IIinduced hypertensive kidney disease in mice. American journal of physiology Renal physiology. 2012; 8: F986-997.

15. Huang XR, Chung AC, Yang F, Yue W, Deng C, Lau CP, Tse HF and Lan HY. Smad3 mediates cardiac inflammation and fibrosis in angiotensin II-induced hypertensive cardiac remodeling. Hypertension. 2010; 5: 1165-1171.

16. Chung AC, Huang XR, Zhou L, Heuchel R, Lai KN and Lan HY. Disruption of the Smad7 gene promotes renal fibrosis and inflammation in unilateral ureteral obstruction (UUO) in mice. Nephrology, dialysis, transplantation : official publication of the European Dialysis and Transplant Association - European Renal Association. 2009; 5: 14431454.

17. Chen HY, Huang XR, Wang W, Li JH, Heuchel RL, Chung $\mathrm{AC}$ and Lan HY. The protective role of Smad7 in diabetic kidney disease: mechanism and therapeutic potential. Diabetes. 2011; 2: 590-601.

18. Liu GX, Li YQ, Huang XR, Wei L, Chen HY, Shi YJ, Heuchel RL and Lan HY. Disruption of Smad7 promotes ANG II-mediated renal inflammation and fibrosis via Sp1TGF-beta/Smad3-NF.kappaB-dependent mechanisms in mice. PloS one. 2013; 1: e53573.

19. Dai XY, Zhou L, Huang XR, Fu P and Lan HY. Smad7 protects against chronic aristolochic acid nephropathy in mice. Oncotarget. 2015; 14: 11930-11944.

20. Schaneberg BT, Mikell JR, Bedir E and Khan IA. An improved HPLC method for quantitative determination of six triterpenes in Centella asiatica extracts and commercial products. Die Pharmazie. 2003; 6: 381-384.

21. Yun KJ, Kim JY, Kim JB, Lee KW, Jeong SY, Park HJ, 
Jung HJ, Cho YW, Yun K and Lee KT. Inhibition of LPSinduced NO and PGE2 production by asiatic acid via NFkappa B inactivation in RAW 264.7 macrophages: possible involvement of the IKK and MAPK pathways. International immunopharmacology. 2008; 3: 431-441.

22. Pittella F, Dutra RC, Junior DD, Lopes MT and Barbosa NR. Antioxidant and cytotoxic activities of Centella asiatica (L) Urb. International journal of molecular sciences. 2009; 9: 3713-3721.

23. Tang LX, He RH, Yang G, Tan JJ, Zhou L, Meng XM, Huang XR and Lan HY. Asiatic acid inhibits liver fibrosis by blocking TGF-beta/Smad signaling in vivo and in vitro. PloS one. 2012; 2: e31350.

24. Xu C, Wang W, Xu M and Zhang J. Asiatic acid ameliorates tubulointerstitial fibrosis in mice with ureteral obstruction. Experimental and therapeutic medicine. 2013; 3: 731-736.

25. Assini JM, Mulvihill EE, Burke AC, Sutherland BG, Telford DE, Chhoker SS, Sawyez CG, Drangova M, Adams AC, Kharitonenkov A, Pin CL and Huff MW. Naringenin prevents obesity, hepatic steatosis, and glucose intolerance in male mice independent of fibroblast growth factor 21 . Endocrinology. 2015; 6: 2087-2102.

26. Mulvihill EE, Assini JM, Sutherland BG, DiMattia AS, Khami M, Koppes JB, Sawyez CG, Whitman SC and Huff MW. Naringenin decreases progression of atherosclerosis by improving dyslipidemia in high-fat-fed low-density lipoprotein receptor-null mice. Arteriosclerosis, thrombosis, and vascular biology. 2010; 4: 742-748.

27. Assini JM, Mulvihill EE, Sutherland BG, Telford DE, Sawyez CG, Felder SL, Chhoker S, Edwards JY, Gros R and Huff MW. Naringenin prevents cholesterol-induced systemic inflammation, metabolic dysregulation, and atherosclerosis in $\operatorname{Ldlr}(-) /(-)$ mice. Journal of lipid research. 2013; 3: 711-724.

28. Liu X, Wang W, Hu H, Tang N, Zhang C, Liang W and Wang M. Smad3 specific inhibitor, naringenin, decreases the expression of extracellular matrix induced by TGFbeta1 in cultured rat hepatic stellate cells. Pharmaceutical research. 2006; 1: 82-89.

29. Lou C, Zhang F, Yang M, Zhao J, Zeng W, Fang X, Zhang Y, Zhang $\mathrm{C}$ and Liang W. Naringenin decreases invasiveness and metastasis by inhibiting TGF-beta-induced epithelial to mesenchymal transition in pancreatic cancer cells. PloS one. 2012; 12: e50956.

30. Li J, Qu X, Yao J, Caruana G, Ricardo SD, Yamamoto Y, Yamamoto $\mathrm{H}$ and Bertram JF. Blockade of endothelialmesenchymal transition by a Smad3 inhibitor delays the early development of streptozotocin-induced diabetic nephropathy. Diabetes. 2010; 10: 2612-2624.

31. Ai J, Nie J, He J, Guo Q, Li M, Lei Y, Liu Y, Zhou Z, Zhu F, Liang M, Cheng Y and Hou FF. GQ5 Hinders Renal Fibrosis in Obstructive Nephropathy by Selectively Inhibiting TGF-beta-Induced Smad3 Phosphorylation. Journal of the American Society of Nephrology : J Am Soc Nephrol. 2015; 26:1827-1838.
32. Lan HY. Smad7 as a therapeutic agent for chronic kidney diseases. Front Biosci. 2008;13:4984-4992.

33. Lan HY, Mu W, Tomita N, Huang XR, Li JH, Zhu HJ, Morishita R and Johnson RJ. Inhibition of renal fibrosis by gene transfer of inducible Smad7 using ultrasoundmicrobubble system in rat UUO model. Journal of the American Society of Nephrology : JASN. 2003; 6: 15351548 .

34. Ka SM, Yeh YC, Huang XR, Chao TK, Hung YJ, Yu $\mathrm{CP}$, Lin TJ, Wu CC, Lan HY and Chen A. Kidneytargeting Smad7 gene transfer inhibits renal TGF-beta/ MAD homologue (SMAD) and nuclear factor kappaB (NF-kappaB) signalling pathways, and improves diabetic nephropathy in mice. Diabetologia. 2012; 2: 509-519.

35. Liu GX, Li YQ, Huang XR, Wei LH, Zhang Y, Feng M, Meng XM, Chen HY, Shi YJ and Lan HY. Smad7 inhibits AngII-mediated hypertensive nephropathy in a mouse model of hypertension. Clin Sci (Lond). 2014; 3: 195-208.

36. Fukasawa H, Yamamoto T, Togawa A, Ohashi N, Fujigaki Y, Oda T, Uchida C, Kitagawa K, Hattori T, Suzuki S, Kitagawa M and Hishida A. Down-regulation of Smad7 expression by ubiquitin-dependent degradation contributes to renal fibrosis in obstructive nephropathy in mice. Proceedings of the National Academy of Sciences of the United States of America. 2004; 23: 8687-8692.

37. Tan $\mathrm{R}, \mathrm{He} \mathrm{W}$, Lin $\mathrm{X}$, Kiss LP and Liu Y. Smad ubiquitination regulatory factor-2 in the fibrotic kidney: regulation, target specificity, and functional implication. American journal of physiology Renal physiology. 2008; 5: F1076-1083.

38. Qin W, Chung AC, Huang XR, Meng XM, Hui DS, Yu CM, Sung JJ, Lan HY. TGF- $\beta /$ Smad3 signaling promotes renal fibrosis by inhibiting miR-29. Journal of the American Society of Nephrology : JASN. 2011;22:1462-1474.

39. Zhong X, Chung AC, Chen HY, Meng XM and Lan HY. Smad3-mediated upregulation of miR-21 promotes renal fibrosis. Journal of the American Society of Nephrology : JASN. 2011; 9: 1668-1681.

40. Zhong X, Chung AC, Chen HY, Dong Y, Meng XM, Li R, Yang W, Hou FF and Lan HY. miR-21 is a key therapeutic target for renal injury in a mouse model of type 2 diabetes. Diabetologia. 2013; 3: 663-674.

41. Chen HY, Zhong X, Huang XR, Meng XM, You Y, Chung AC, Lan HY. MicroRNA-29b inhibits diabetic nephropathy in $\mathrm{db} / \mathrm{db}$ mice. Mol Ther. 2014;22:842-853.

42. Zhong Y, Menon MC, Deng Y, Chen Y and He JC. Recent Advances in Traditional Chinese Medicine for Kidney Disease. American journal of kidney diseases : the official journal of the National Kidney Foundation. 2015.

43. Lan HY, Mu W, Nikolic-Paterson DJ and Atkins RC. A novel, simple, reliable, and sensitive method for multiple immunoenzyme staining: use of microwave oven heating to block antibody crossreactivity and retrieve antigens. The journal of histochemistry and cytochemistry : official 
journal of the Histochemistry Society. 1995; 1: 97-102.

44. Meng XM, Huang XR, Xiao J, Chung AC, Qin W, Chen HY and Lan HY. Disruption of Smad4 impairs TGF-beta/ Smad3 and Smad7 transcriptional regulation during renal inflammation and fibrosis in vivo and in vitro. Kidney international. 2012; 3: 266-279. 